Kansas State University Libraries

New Prairie Press

\title{
EVALUATION OF THE THREE PLANTAIN (MUSA AAB) CULTIVARS FOR AGRONOMIC CHARACTERISTICS
}

\author{
Ahmad R. Rafie \\ Carlos Medina
}

Follow this and additional works at: https://newprairiepress.org/agstatconference

Part of the Agriculture Commons, and the Applied Statistics Commons

\section{(c) (1) $\Theta(9$}

This work is licensed under a Creative Commons Attribution-Noncommercial-No Derivative Works 4.0 License.

\section{Recommended Citation \\ Rafie, Ahmad R. and Medina, Carlos (1989). "EVALUATION OF THE THREE PLANTAIN (MUSA AAB) CULTIVARS FOR AGRONOMIC CHARACTERISTICS," Conference on Applied Statistics in Agriculture. https://doi.org/10.4148/2475-7772.1455}

This is brought to you for free and open access by the Conferences at New Prairie Press. It has been accepted for inclusion in Conference on Applied Statistics in Agriculture by an authorized administrator of New Prairie Press. For more information, please contact cads@k-state.edu. 


\title{
EVALUATION OF THE THREE PLANTAIN (MUSA AAB) CULTIVARS FOR AGRONOMIC CHARACTERISTICS
}

\author{
Ahmad R. Rafie and Carlos Medina \\ Fundacion Hondureña de Investigacion Agricola (FHIA) \\ La Lima, Honduras
}

\begin{abstract}
Plantains (Musa $A A B$ ) are widely used as a source of carbohydrate in Latin America and Africa. The most commonly grown plantain cultivar, "Horn plantain" is tall which makes it susceptible to losses by wind. Recently, two dwarf mutants of "Horn plantain" were selected. A randomized complete block design experiment with four replications was conducted to compare the agronomic characteristics of the dwarf mutants with those of the traditional cultivar. The data was analyzed as if the experiment was strip-plot design with cultivar as the horizontal factor and harvest as the vertical factor. "Analysis of variance" and "Least significant difference" test were used for data analysis. The results indicated that one of the mutants produces a heavier fruit bunch than the tall cultivar and also meets the finger length and finger caliper specifications for export purposes.
\end{abstract}

\section{INTRODUCTION}

Bananas originated in Southeast Asia and constitute a distinctive group within the order zingiberales, Family Musaceae, Genus Musa and Section Eumusa (5). All the edible bananas originated from Musa acuminata and Musa balbisiana, members of the Section Eumusa, and have 22, 33, or 44 chromosomes. The basic chromosome number is $n=11$, so that these cultivars are respectively diploid, triploid and tetraploid. Triploids are generally the most numerous, diploids somewhat less so and tetraploids are rare (7). It is generally believed that triploids are predominant among the cultivated bananas because they have been selected for superiority over diploids in terms of vegetative vigor and yield (7).

The first steps in the evolution of the edible banana were the development of parthenocarpy and seed-sterility in Musa acuminata. Parthenocarpy is the capacity of the fruit to grow and become full of edible parenchymatous pulp without

pollination. Seed sterility is due to cytogenetic factors and is also very important because banana seeds are stony and most unpleasant to encounter (6). Edibility, therefore, is parthenocarpy plus sterility. 
Ploidy and genomic composition of the different clones are designated by $A$ and $B$ to represent the genomes of Musa acuminata and Musa balbisiana, respectively. Base $\bar{d}$ on the chromosome number and scoring for the preponderance of characteristics from each of the two parental species, these $A$ and $B$ abbreviations are used to form Groups for classification and identification of specific cultivars (6).

From the AA cultivars, by chromosome restitution at meiosis, there arose the AAA triploids (the export bananas are AAA triploids). Another important step was the crossing of $A A$ (and perhaps $A A A)$ cultivars with wild Musa balbisiana (BB). Musa balbisiana is a hardier and more drought-tolerant plant than Musa acuminata. The hybrid groups not only enlarged the range of plant characteristics and quality features but also helped to extend the geographical range of the bananas out of the wetter tropics into the seasonally drier zones. All plantains ( $A A B$ ) are hybrids between these two parental species (7). Plantains are a major source of carbohydrate for millions of people in Latin America and Africa (3).

The most commonly grown plantain cultivar is the tall "Horn plantain". The height of the plant results in frequent losses from strong wind. Recently, two dwarf mutants (Plant Baja I and Planta Baja II) of Horn plantain were selected. This study was undertaken to study and compare the agronomic characteristics of the two dwarf mutants with that of the tall standard cultivar.

\section{MATERIALS AND METHODS}

Planta Baja I and Planta Baja II were selected in 1985 from the collection of Programa Nacional de Plátano del Ministerio de Recursos Naturales in Honduras. The selected plants were propagated using meristem culture and planted in the field in 1987 when the experiment was initiated.

In banana and plantain, the mother plant is cut off after the harvest of the fruit (first harvest). A sucker plant will grow from the base of the mother plant to generate another mother plant for the second harvest (from harvest to harvest will take approximately one year). It is well established that in banana and plantain experimentation, the effect of the treatments, can not be determined with the first harvest. Several harvests from the same experimental plots are needed to accurately determine the effects of the treatments. It is customary to analyze the data obtained for each harvest separately. Since the effect of each treatment (cultivar) varies from one harvest to the next harvest, we decided to analyze several harvests jointly in order to observe the interaction between cultivars and harvests. This experiment will continue up to the fourth harvest. The results presented in this paper are based on the first two harvests. Plant 
population was 1900 plant per hectare. Planting was on a hexagonal basis with spacing between plants at 2.5 meters.

A randomized complete block design experiment with four replications was conducted at Centro Experimental Demostrativo Guaruma, La Lima, Honduras. The experimental unit (plot) consisted of 20 plants in which the measurements were taken from each individual plant for variables under consideration for each harvest. Sampling error was used to measure the variation from plant to plant and experimental error for mean plot to plot variation. Appropriate experimental error was used to test the effect of the cultivars (error a), harvest (error b) and interaction between harvest and cultivar (error c). Variables analyzed were "finger length" "Finger caliper" (both important for determining compliance with export specifications) and "Bunch weight". Since the same plots with the same arrangements of plants are harvested over time, it is more appropriate to analyze the data as a strip-plot design with cultivar as the horizontal factor and harvest as the vertical factor (1). ISD test with appropriate standard errors (2) was used to compare the means of all pairs of cultivar (even though, Horn plantain appears as "control", we are also interested in comparing the planta Baja I and Planta Baja II).

\section{RESULTS AND DISCUSSION}

Table 1 shows the plot means (20 plants per plot) of fruit bunch, finger length and finger caliper for each plot, each harvest, each replication and each cultivar.

Table 2 shows the results from analysis of variance (4) for variable bunch weight. The results indicate that there was no interaction between the harvest and cultivar for this variable, indicating that the harvest difference was not significantiy affected by different cultivars. The main effects of both cultivar and harvest were significantly different. since the interaction was not significant, cultivars were compared averaged over the two harvests (Table 2). For this variable the sampling error as the measure of the plant to plant variation was lower in comparison to the experimental errors.

Table 3 shows the means of the three cultivars for bunch weight averaged over both harvests. Using ISD test, only the difference between the means for bunch weight of Planta Baja II and Horn plantain was statistically significant, indicating that cultivar Planta Baja II was capable of producing heavier bunches in comparison with the Horn plantain cultivar. The difference between the means of bunch weight for Planta Baja I and Horn plantain ( $1.59 \mathrm{~kg} / \mathrm{plant})$, and also, the difference between the means of the Planta Baja II and Planta Baja I ( $1.03 \mathrm{~kg} / \mathrm{plant}$ ) were noticeable. Although these differences are not statistically significant, converted on a per hectare basis (1957 kg/hectar and $3021 \mathrm{~kg} /$ hectar, respectively), they become economically important. 
Table 1. Plot means for variables analyzed.

\begin{tabular}{clllll}
\hline Harvest & Cultivar & Rep. & $\begin{array}{c}\text { Fruit } \\
\text { Bunch }\end{array}$ & $\begin{array}{c}\text { Finger } \\
\text { lenght }\end{array}$ & $\begin{array}{l}\text { Finger } \\
\text { Caliper }\end{array}$ \\
\hline I & Horn & A & 14.28 & 30.48 & 26.68 \\
I & Horn & B & 14.03 & 29.58 & 26.48 \\
$I$ & Horn & C & 13.18 & 30.24 & 26.20 \\
$I$ & Horn & D & 14.15 & 29.95 & 25.63 \\
$I$ & Baja I & A & 16.13 & 25.41 & 21.00 \\
$I$ & Baja I & B & 14.93 & 25.26 & 20.65 \\
$I$ & Baja I & C & 15.65 & 25.65 & 20.68 \\
I & Baja I & D & 16.25 & 26.10 & 21.10 \\
$I$ & Baja II & A & 15.98 & 27.02 & 22.30 \\
$I$ & Baja II & B & 16.70 & 26.85 & 22.08 \\
$I$ & Baja II & C & 15.53 & 27.25 & 21.63 \\
$I$ & Baja II & D & 16.83 & 26.81 & 21.23 \\
2 & Horn & A & 16.50 & 26.93 & 23.16 \\
2 & Horn & B & 14.58 & 26.21 & 21.83 \\
2 & Horn & C & 15.08 & 27.35 & 23.03 \\
2 & Horn & D & 15.78 & 27.25 & 23.03 \\
2 & Baja I & A & 17.65 & 25.57 & 22.15 \\
2 & Baja I & B & 14.63 & 23.57 & 20.13 \\
2 & Baja I & C & 15.75 & 24.45 & 21.28 \\
2 & Baja I & D & 15.78 & 27.25 & 23.03 \\
2 & Baja II & A & 16.90 & 26.65 & 22.45 \\
2 & Baja II & B & 19.20 & 26.70 & 21.83 \\
2 & Baja II & C & 19.05 & 26.45 & 23.55 \\
2 & Baja II & D & 18.38 & 27.26 & 24.00 \\
& & & & & \\
\hline
\end{tabular}

Table 2. Analysis of variance for "Bunch weight" (Strip plot design).

\begin{tabular}{lrrrr}
\hline SOUICe & df & \multicolumn{1}{c}{ SS } & \multicolumn{1}{c}{ MS } & Pr. \\
\hline REPLICATION & 3 & 99.89 & 33.30 & \\
CULTIVAR & 2 & 562.89 & 281.44 & 0.019 \\
ERROR(a) & 6 & 202.96 & 33.83 & \\
HARVEST & 1 & 307.20 & 307.20 & 0.008 \\
ERROR (b) & 3 & 23.36 & 7.89 & \\
HARVEST ${ }^{*}$ CULTIVAR & 2 & 20.59 & 10.29 & 0.579 \\
ERROR(c) & 6 & 102.94 & 17.16 & \\
SAMPLING ERROR & 456 & 2028.70 & 4.45 & \\
& & & & \\
\hline
\end{tabular}


Table 3. Means of the cultivars averaged over both harvests, using the LSD test.

\begin{tabular}{cc}
\hline Cultivars & $\begin{array}{c}\text { Means bunch weight } \\
\text { (kg/plant) }\end{array}$ \\
\hline Planta Baja II & 17.32 \\
Planta Baja I & 16.29 \\
Horn plantain & 14.70 \\
\hline
\end{tabular}

LSD $=1.60 \mathrm{~kg} /$ plant.

Significant level $=5 \%$

Table 4 and 5 show the analysis of variance for variables finger length and inger caliper, two very important variables for export purposes (acceptable finger length and finger caliper for export purposes are $25 \mathrm{~cm}$ and $20 \mathrm{~mm}$ respectively). In both tables there are interactions between cultivar and harvest, indicating that harvests difference was affected by cultivars differences. Figures 1 and 2 show these interactions graphically. Due to the presence of interaction between harvest and cultivar for finger length and finger caliper, cultivars were compared for each harvest separately. Another point which is worth mentioning is the magnitude of the sampling error for variable finger caliper which was larger than that for error (a) and error (b), indicating that plant to plant variation was larger than plot to plot variation. This is not very surprising in dealing with banana and plantain research. Even though, the plants in the plantation. in most cases, are from the same clone, variation from plant to plant within the same plot is noticeable regardless of the environmental factors.

Table 4. Analysis of variance for "Finger length" (strip plot design).

\begin{tabular}{lrrrr}
\hline SOUICe & dF & \multicolumn{1}{c}{ SS } & \multicolumn{1}{c}{ MS } & Pr. \\
\hline REPLICATION & 3 & 43.28 & 14.43 & \\
CULTIVAR & 2 & 869.29 & 434.64 & 0.0001 \\
ERROR(a) & 6 & 23.57 & 3.93 & \\
HARVEST & 1 & 231.44 & 231.44 & 0.005 \\
ERROR(b) & 3 & 12.37 & 4.12 & \\
HARVEST* CULTIVAR & 2 & 190.48 & 95.24 & 0.001 \\
ERROR(c) & 6 & 20.22 & 3.37 & \\
SAMPING ERROR & 456 & 1491.57 & 3.27 & \\
& & & &
\end{tabular}




\section{Finger}

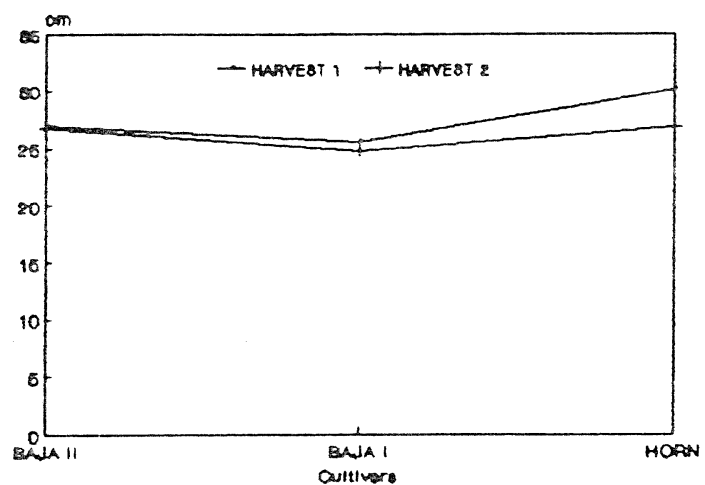

Fig. 1 and 2. Means of cultivars for each harvest for variables finger length and finger caliper.

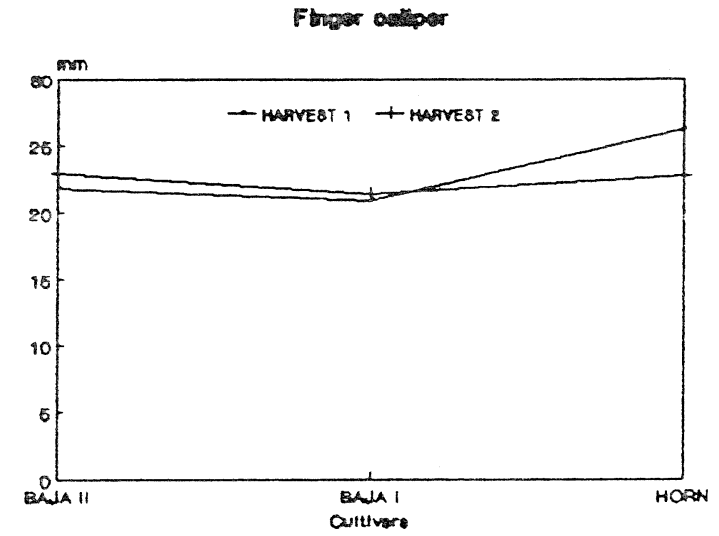


Table 5. Analysis of variance for "Finger caliper" (strip plot
design).

\begin{tabular}{|c|c|c|c|c|}
\hline source & $d f$ & SS & MS & Pr. \\
\hline REPLICATION & 3 & 44.90 & 14.97 & \\
\hline CULTIVAR & 2 & 925.30 & 462.65 & 0.0001 \\
\hline $\operatorname{ERROR}(\mathrm{a})$ & 6 & 20.14 & 3.36 & \\
\hline HARVEST & 1 & 42.07 & 42.07 & 0.295 \\
\hline $\operatorname{ERROR}(\mathrm{b})$ & 3 & 78.82 & 26.27 & \\
\hline HARVEST*CULTIVAR & 2 & 510.34 & 255.17 & 0.0001 \\
\hline ERROR (c) & 6 & 23.01 & 3.84 & \\
\hline SAMPLING ERROR & 456 & 2426.65 & 5.32 & \\
\hline
\end{tabular}

Table 6 shows the means of the cultivars for variables finger length and finger caliper for each harvest. Using LSD test, we see that for variable finger length, during harvest 1 , Horn plantain produced longer fingers in comparison with the other cultivars. For the first harvest the differences between Horn plantain and both Planta Baja I and Planta Baja II are statistically significant, as is the difference between Planta Baja I and Planta Baja II. However, in the second harvest, the difference between the means of Horn plantain and Planta Baja II were not statistically significant, which is due to the greater reduction of the finger length for Horn plantain than for Planta Baja II. The difference between Horn plantain and Planta Baja I remained statistically significant. Also the difference between the means of Planta Baja I and Planta Baja II remained significant. For variable finger caliper, the differences between the means of Horn plantain and Planta Baja I, and also Horn plantain and Planta Baja II were statistically significant during the first harvest. For the second harvest, the mean for Horn plantain was reduced, while the means for the other two cultivars increased. The difference between the means of the Horn plantain and Planta Baja I remained significant regardless of the decrease of the mean for Horn plantain and increase of the mean for the Planta Baja I and the difference between the means for the Horn plantain and Planta Baja II became statistically insignificant in the second harvest due to increase in the finger caliper for Planta Baja II and reduction on the finger caliper for Horn plantain. 
Table 6. Means of the cultivars for individual harvest, using LSD test.

\begin{tabular}{lccccc}
\hline & \multicolumn{2}{c}{$\begin{array}{c}\text { Finger lenght } \\
\text { (cm) }\end{array}$} & & \multicolumn{2}{c}{$\begin{array}{c}\text { Finger caliper } \\
\text { (mm) }\end{array}$} \\
Cultivars & HI & H2 & & HI & H2 \\
\hline Horn Plantain & 30.06 & 26.92 & & 26.25 & 22.76 \\
Planta Baja I & 25.60 & 24.79 & & 20.86 & 21.42 \\
Planta Baja II & 26.98 & 26.76 & & 21.81 & 22.96 \\
\hline HI = Harvest I & LSD $=0.66 \mathrm{~cm}$ & & LSD $=0.65 \mathrm{~mm}$ \\
H2 = Harvest 2 & & & & & \\
Significant level & 58 & & & &
\end{tabular}

\section{CONCLUSION}

The selected mutant cultivars (Planta Baja I and Planta Baja II) produced heavier bunches than the traditional Horn plantain cultivar. In addition, although the Horn plantain produced longer and thicker fingers during the first harvest, Planta Baja II produced fingers as long and as thick as those for Horn plantain during the second harvest. It appears from analysis of these two harvests, therefore, that Planta Baja II has good exportation potential since finger length and finger caliper from both harvests meet the export standards.

Planta Baja I is not exhibiting this same potential for export, having finger length and finger caliper at the borderline of the standard. This cultivar could be used for local consumption, where only the bunch weight is considered important. It is interesting to notice that based on this data the behavior of the Horn plantain varies more from one harvest to the other for variables analyzed in comparison to the Planta Baja I and Planta Baja II.

More concrete conclusions about the potential of Planta Baja II as an alternative to the Horn plantain for production of plantain for export will be made after analysis of the remaining two harvests. 


\section{REFERENCES}

1. Cochran, William G., and Gertrude M. Cox. 1957. Experimental Design, 2nd ed., Wiley, New York.

2. Gomez, Kwanchai a., and Arturo A. Gomez. 1984. Statistical Procedures for Agricultural Research, 2nd ed.. Wiley. New York.

3. Rowe, Phillip. 1984. Plant Breeding Reviews, Vol. 2 page 135-155. In Jules Janick (ed.) Breeding Bananas and Plantains. The AVI, Westport, Ct.

4. SAS Institute. 1987. SAS/STAT Guide for personal Computers SAS Inst., Cary, NC.

5. Simmonds, N.W. 1962. The Evolution of the Bananas. Iongmans Scientific and Technical, London.

6. Simmonds, N.W. 1966. Bananas. Longmans Scientific and Technical, London.

7. Stover, R.H. and N.W. Simmonds. 1987. Bananas. Longmans Scientific and Technical, London. 